\title{
Flaws in GINA Guidelines and the Solutions Thereof
}

\section{Prahalad Gupta* \\ Department of Respiratory Medicine, NIMS University, India}

*Corresponding author: Prahalad Gupta, Department of Respiratory Medicine, NIMS University, J aipur, India

Received: December 19, 2016; Accepted: J anuary 18, 2017; Published: J anuary 20, 2017

\begin{abstract}
Asthma continues to be the commonest chronic respiratory illness and its prevalence is on the rise. Further, its control remains poor in spite of the wide availability and practice of GINA guidelines. Based on literature, the author is of the opinion that asthma can be better controlled with "Step in-Step down approach" (Initiating treatment of asthma with optimal dose of ICS along with LABA, withdrawal of LABA first during step down and finally reducing dose of ICS once control of asthma is sustained) rather than the Step up-step down approach" suggested by GINA.
\end{abstract}

Keywords: Asthma; Long Acting Beta Agonists (LABA); Global Initiative for Asthma (GINA)

\section{Introduction}

With an estimated prevalence of 300 million patients globally, asthma tops the list of chronic respiratory illnesses. Further, its prevalence is increasing in many countries, especially in children and it is emerging as the leading cause of school and work days lost. The health care expenditure on asthma is also very high.

Several studies have already demonstrated that the level of asthma control is closely linked to the use of healthcare resources, the level of lifestyle impairment, and QoL: the better is the control, the less is impairment, the lower is the use of healthcare resources and the higher is the QoL [1-6].

GINA (The Global Initiative for Asthma), first published its guidelines to control asthma, in the year, 1995. Ever since then it is updating its guidelines. As per the guidelines, the diagnosis of asthma is to be made when there is 1) History of characteristic symptom patterns, 2) Evidence of variable airflow limitation and 3) Bronchodilator reversibility test is positive. For management of asthma, it has suggested the "Step up Step down approach" [7]. It has also suggested a plan to manage acute exacerbation as well.

The last update on asthma has been published in the year 2016 [8]. Key changes in GINA-2016 include 1) Addition of Low-dose fluticasone furoate/vilanterol as an option at step 3,2) Addition of tiotropium as an add-on option at Step 4 and 3) Expert investigation and add-on treatment options at step 5. Other therapies mentioned in guidelines include vitamin D supplementation, allergen immunotherapy, vaccinations and bronchial thermoplasty. For lowresource settings, it has suggested augmentation of resources for correct diagnosis of asthma including the use of Peak flow meter as an essential tool and to rule out other chronic respiratory infections e.g. tuberculosis. For management of asthma it has suggested to prioritize cost-effective approach. To assess control of asthma, it has now recommended use of established criteria for control of asthma.

\section{What is the status of control of asthma globally?}

GINA guidelines to control asthma are in place for many years but surveys in Europe, Asia-Pacific \& USA says that control of asthma continues to be poor [9-11]. The latest statistics in UK (2016) [12] says that 1) Every 10 seconds someone in UK has a potentially lifethreatening asthma attack, 2) Three people every day/1000 persons every year die of asthma and two thirds of these deaths could be prevented and 3) Others still suffer with asthma so severe that current treatments don't work. Thus it is clear that control of asthma continues to be poor despite the existence of.

\section{GINA guidelines}

GINA has not made any major change in its treatment guidelines in its latest update (2016) so as to make any worthwhile impact on the treatment outcomes in asthma. What is then the road map ahead?

The possible reasons for poor control of asthma may lie in: 1) Guideline based treatment is not followed, 2) Compliance to treatment is poor and 3) Guidelines are not robust enough to control asthma under field conditions. To unreal the cause for poor control, let us look back and review the existing literature!

\section{ICS and asthma}

Inhaled Corticosteroids (ICS) are the key drugs in the management of asthma as it: 1) Reduce Airway Inflammation, 2) Improve Pulmonary Functions, 3) Reduce Bronchial HyperReactivity (BHR) and 4) Reverse airway remodeling. Response to ICS, however, depends on: 1) Timely introduction of ICS, 2) Coprescription with $\beta_{2}$ agonists and 3) Optimal dose Of ICS.

Delayed Introduction of ICS leads to irreversible changes in airway pathology [13]. Further, ICS gives better clinical response when used along with $\beta_{2}$ agonists $[14,15]$. A recent study has also revealed that ICS+LABA caused a more rapid improvement in different asthma control measures compared with ICS alone [16].

\section{Dose of ICS \& control of asthma}

Conventional drug trials have revealed that the effect of ICS is dose dependent until a plateau is reached $[17,18]$ Single Maintenance and Reliever Therapy (SMART) trials have also revealed that SMART treated patients (Who incidentally received higher doses of ICS than those on conventional dose schedule), showed better control asthma [19]. What does this mean? Higher dose ICS schedules led to better control of asthma than lower dose ICS schedules. 


\section{Low dose ICS along with LABA}

Powels et al. were the first to show that low dose of ICS when used along with LABA gives better response than doubling the dose of ICS [14]. Other workers, including Woolcock et al. [15] reiterated the same. This led to widespread use of LABA along with low dose ICS, mostly in fixed dose formulations. This continued despite the observations made by Bhagat et al. [20] that the long term use of LABA along with low dose ICS led to tolerance. The underlying reason for the same was unrevealed by animal studies showing that ICS in optimal doses is critical to avoid pro-inflammatory effects of $\beta_{2}$ agonists and if threshold of total $\beta_{2}$ agonist exposure is crossed, ICS may fail to protect against these adverse effects of $\beta_{2}$ agonists [21-24]

Although, the safety of use of Low dose of ICS along with LABA in humans has been confirmed in 2 recent meta-analyses $[25,26]$ but it should also be kept in mind that 1) These results were obtained under trial conditions, 2) More deaths were reported in such patients as compared to those who received higher dose of ICS and 3) Almost all the studies have studied the efficacy/safety of low dose ICS+LABA but has not compared it to that with high dose ICS+LABA.

\section{The "FACET Study"}

Formoterol and Corticosteroids Establishing Therapy (FACET) is the only study that compared the efficacy of Low dose ICS and high dose ICS when used along with LABA" in control of mild to moderate asthma [14]. Yet this study has been often misquoted and widely misused to propagate the use of low dose ICS+LABA in asthma. Gupta [26] has revisited the "FACET study". Accordingly, what has been learnt from the "FACET study" is that "Addition of LABA to low dose ICS is more effective than doubling the dose of ICS in control of asthma" but what hasn't been learnt is that "Addition of LABA to a higher dose of ICS leads to more effective control of asthma than addition of LABA to low dose ICS", both, in short term as well as the long term".

Tukiainen et al. [17] and Inman et al. [18] have observed that higher doses of ICS led to more effective control of asthma, not only in terms of better clinical response and pulmonary functions but also in terms of decreased airway hyper-reactivity and surrogate markers of inflammation. Green et al. [27] showed that when sputum eosinophillia was used as criteria for control of asthma (as compared to control of symptoms alone), there were fewer exacerbations and hospitalizations. These studies also established the fact that "Symptomatic control of asthma does not necessarily mean the best control of asthma".

\section{The GOAL study}

Gaining Optimal Asthma Control (GOAL) [28] is the other study worth discussion in this context. It was a multicentric study where patients with sub-optimally controlled asthma were stratified based on their use of ICS before the study i.e. a) Stratum 1: Patients who were not taking steroids, b) Stratum 2: Patients who were taking $500 \mathrm{mcg}$ or less of beclomethasone dipropionate or equivalent and c) Stratum 3:.Patients were taking 500 to $1000 \mathrm{mcg}$ or less of beclomethasone dipropionate or equivalent. During phase 1 of the study (dose escalation phase), treatment was stepped up every 12 weeks until either asthma was totally controlled or a dose of Salmeterol-Fluticasone (SF) 50-500 mcg twice daily or Fluticasone
(F) $500 \mathrm{mcg}$ twice daily (maximum dose) was reached. At this stage, these patients entered into phase 2 (dose maintenance phase), where treatment was continued without any tapering upto 1 year.

Of the total 3421 patients initially included in the study, Phase 1 was completed by 3039 patients and phase 2, by 2890 patients. About $68 \%$ and $76 \%$ of patients were receiving the highest dose of S/F and $\mathrm{F}$ at 1 year, respectively, across all the strata. Total control was achieved on $\mathrm{S} / \mathrm{F}$ and $\mathrm{F}$ alone in $31 \%$ and $19 \%$ after phase $1(\mathrm{P}<.001)$ and $40 \%$ and $28 \%$ after phase 2, respectively. Good control was achieved in $63 \%$ and $50 \%(\mathrm{P}<.001)$ and $71 \%$ and $59 \%$ patients, respectively.

Important inferences drawn out of the study included: a) Not all poorly controlled asthma patients included in the study, achieved a total asthma control despite use of high doses of ICS+LABA or ICS over a prolonged period $b$ ) Most patients taking high doses of ICS+LABA or ICS for between 7 and 10 months were well controlled, c) Control was achieved more rapidly and at a lower dose with ICS+LABA than with ICS alone d) Exacerbation rates were significantly lower with ICS+LABA than with ICS alone in each stratum.

But what has been not been emphasized out of this study includes the following: a) Even higher dosage of ICS alone or along with LABA fails to control asthma, once asthma is allowed to go out of control at initial stage and b) Add on LABA makes a significant difference only during initial part of therapy i.e. till control is achieved/highest dose of ICS is reached (Phase 1 of therapy) and not so thereafter (phase 2). In other words, treatment in asthma should be initiated early, with appropriate dosage of ICS and that too along with LABA.

Initiating treatment with higher dose ICS in asthma has other advantages too: 1) It obviates the need for systemic steroids and 2) It allows the discontinuation of systemic steroids. The risk of adverse effects of higher dose of ICS are obvious but it can be checked by rinsing the mouth with water after the use of dry powder inhaler or the use of a spacer device with metered dose inhalers. Further, the dose ICS can be reduced once sustained control is obtained.

From the above discussion, it can be easily inferred that initiating therapy with optimal dose of ICS and LABA is superior to that with $\beta_{2}$ agonist, as needed, low dose ICS alone or low dose ICS and LABA recommended in GINA guidelines.

\section{Step down in asthma}

As per GINA guidelines, step down usually means reducing the dose of ICS first but Gupta and Jain [29] has questioned this policy? Animal studies have already shown that $\beta_{2}$ agonists can be proinflammatory if used for long time [21-23]. Clinically also, Bhagatet al. [20] have shown that Long Term use of LABA with low dose ICS may lead to tolerance.

In a patient on prolonged LABA, without or with low dose ICS, control of asthma as based on symptomatic control or pulmonary functions may be misleading. LABA exerts masking effect on airway inflammation and thus a patient may remain symptom free even when the underlying airway inflammation is continued. Food and Drug Administrator (US FDA) continues to be worried on long term use of LABA and recommends that as far as possible LABA should be withdrawn first $[30,31]$. In children, it has already mandated that LABA should be withdrawn first. For adults, FDA has Mandated 5 
large scale safety studies [32].

Therefore, in adults also, LABA should be withdrawn first and dose of ICS should be reduced only when sustained control has been obtained.

\section{Conclusion}

In short, the GINA guideline recommendations are unrealistic, more so in field conditions. For better control of asthma, one should: 1) Initiate treatment with optimal dose of ICS along with LABA (800 $\mu \mathrm{g}$ of beclomethasone or equivalent), 2) Step down treatment with withdrawal of LABA first and 3) Reduce dose of ICS once control of asthma is sustained, rather than following GINA guidelines. Obviously loss of control will be more frequent when LABA is withdrawn first but at the same time it is also recognized early and then one should revert back to optimal dose of ICS and LABA. These recommendations have already been discussed by Gupta and Jain [29] as "Step in-step down approach" in asthma and are more close to National asthma education and prevention programme guidelines [32].

\section{References}

1. Vollmer WM, Markson LE, O'Connor E, Frazier EA, Berger M, Buist AS Association of asthma control with health care utilization: a prospective evaluation. Amer J Respir Crit Care Med. 202; 165: 195-199.

2. Schatz M, Mosen D, Apter AJ, Zeiger RS, Vollmer WM, Stibolt TB, et al Relationships among quality of life, severity, and control measures in asthma: an evaluation using factor analysis. J Allergy Clin Immunol. 2005; 115: 10491055.

3. Chen H, Gould MK, Blanc PD, Miller DP, Kamath TV, Lee JH, et al. Asthma control, severity, and quality of life: quantifying the effect of uncontrolled disease. J Allergy Clin Immunol. 2007; 120: 396-402.

4. Sullivan SD, Wenzel SE, Bresnahan BW, Zheng B, Lee JH, Pritchard M, et al Association of control and risk of severe asthma-related events in severe or difficult-to-treat asthma patients. Allergy. 2007; 62: 655-660.

5. Bateman ED, Bousquet J, Keech ML, Busse WW, Clark TJ, Pedersen SE. The correlation between asthma control and health status: the GOAL study. The Eur Respir J. 2007; 29: 56-62.

6. Chapman KR, Boulet LP, Rea RM, Franssen E. Suboptimal asthma control: prevalence, detection and consequences in general practice. Eur Respir J. 2008; 31: 320-325.

7. Global Initiative for Asthma (GINA)-2012. Global strategy for asthma management and prevention.

8. Global Initiative for Asthma-2016. Global Strategy for Asthma Management and Prevention.

9. Rabe KF, Vermeire PA, Soriano JB, Maier WC. Clinical management of asthma: The Asthma Insights and Reality in Europe study. Eur Respir J. 2000; 16: 802-807.

10. Lai CK, De Guia TS, Kim YY, Kuo SH, Mukhopadhyay A, Soriano JB, et al. Asthma control in Asia-Pacific region: The Asthma Insights and Reality in Asia-Pacific study. J Allergy Clin Immunol. 2003; 111: 263-268.

11. Neffen H, Fritscher C, Schacht FC, Levy G, Chiarella P, Soriano JB, et al. Asthma control in Latin America: The Asthma Insights and Reality in Latin America survey. J Pub Health. 2005; 117: 191-197.

12. Asthma UK-2016. Asthma facts and statistics.

13. SelroosO, pietinalho A, Lofroos A B and Riska $\mathrm{H}$. Effect of early v/s late intervention with inhaled cortico-steroids in asthma. Chest. 1995; 108: 12281234.
14. Pauwels RA, Löfdahl CG, Postma DS, Tattersfield AE, O’Byrne P, Barnes $\mathrm{PJ}$, et al. Effect of inhaled formoterol and budesonide on exacerbations of asthma. N Engl J Med. 1997; 337: 1405-1411.

15. Woolcock A, Lundback B, Ringdal N, Jacques LA. Comparison of addition of salmeterol to inhaled steroids with doubling of the dose of inhaled steroids. Am J Respir Crit Care Med. 1996; 153: 1481-1488.

16. Matsunaga $\mathrm{K}$, Kawabata $\mathrm{H}$, Hirano $\mathrm{T}$, Sugiura $\mathrm{H}$, Minakata $\mathrm{Y}$, Ichinose $M$. Difference in time-course of improvement in asthma control measures between budesonide and budesonide/formoterol. Pulm Pharm Therap. 2013; 26: 189-194.

17. Tukiainen H, Taivainen A, Majander R, Poussa T, Svahn T, Puolijoki H. Comparison of high and low dose of the inhaled steroid, budesonide, as an initial treatment in newly detected asthma. Respir Med. 2000; 94: 678-683.

18. Inman MD, Watson RM, Rerecich T, Gauvreau GM, Lutsky BN, Stryszak $P$, et al. Dose-dependent Effects of Inhaled MometasoneFuroate on Airway Function and Inflammation After Allergen Inhalation Challenge. Am J Respir Crit Care Med. 2001; 164: 569-574.

19. Humbert M, Andersson TL, Buhl R. Budesonide/formoterol for maintenance and reliever therapy in the management of moderate to severe asthma. Allergy. 2008; 63: 1567-1580.

20. Bhagat R, Kalra S, Swystun VA, Cockcroft DW. Rapid onset of tolerance to the bronchoprotective action of salmeterol. Chest. 1995; 108: 1235-1239.

21. P Panina-Bordignon, D Mazzeo, P D Lucia, D D'Ambrosio, R Lang, L Fabbri, et al. Beta2-agonists prevent Th1 development by selective inhibition of interleukin-12. J Clin Invest. 1997; 100:1513-1519.

22. Callaerts-Vegh Z, Evans KL, Dudekula N, Cuba D, Knoll BJ, Callaerts PF, et al. Effects of acute and chronic administration of beta-adrenoceptor ligands on airway function in a murine model of asthma. Proc Natl Acad Sci USA. 2004; 101: 4948-4953.

23. McGraw DW, Liggett SB. Molecular mechanisms of beta2-adrenergic receptor function and regulation. Proc Am Thorac Soc. 2005; 2: 292-296.

24. Ducharme F M, Ni Chroinin M, Greenstone I and Lasserson T J. Addition of long-acting beta2-agonists to inhaled steroids versus higher dose inhaled steroids in adults and children with persistent asthma. Cochrane Database Syst Rev. 2010; 4: CD005533.

25. Cates C J, Jaeschke R, Schmidt S, Ferrer M. Regular treatment with formoterol and inhaled steroids for chronic asthma: serious adverse events. Cochrane Database Syst Rev. 2013; 6: CD006924.

26. Gupta PR. Revisiting the FACET Study is the Need of Hour. Aller Asth \& Bronc. 2015, 1: 1.

27. Green RH, Brightling CE, McKenna S, Hargadon B, Parker D, Bradding P et al. Asthma exacerbations and sputum eosinophil counts: a randomised controlled trial. Lancet. 2002; 360: 1715-1721.

28. Bateman ED, Boushey HA, Bousquet J, Busse WW, Clark TJ, Pauwels RA, et al. Can guideline-defined asthma control be achieved? The Gaining Optimal Asthma Control Study. Am J Respir Crit Care Med. 2004; 170: 836844.

29. Gupta P R and Jain S. Stepping down in asthma. Ind J Chest Dis AI Sc. 2013; 55: 117-119.

30. Fanta CH. Asthma. N Engl J Med. 2009; 360: 1002-1014.

31. Chowdhary BA, Seymour SM, Levenson MS. Assessing the safety of adding LABAs to inhaled corticosteroids for treating asthma, New Engl J Med. 2011; 363: 2473-2475.

32. National asthma education and prevention programme guidelines. 